\title{
Assessing Big Data Analytics Capability and Sustainability in Supply Chains
}

\author{
Cetindamar, D. \\ University of Technology Sydney \\ Sydney, Australia \\ Dilek.ck@uts.edu.au
}

\author{
Shdifat, B. \\ University of Technology Sydney \\ Sydney, Australia \\ Baraah.shdifat@student.uts.edu.au
}

\author{
Erfani, S. \\ University of Technology Sydney \\ Sydney, Australia \\ Shadi.Erfani@uts.edu.au
}

\begin{abstract}
:
Big data analytics capability (BDAC) is a technologybased capability, which can influence sustainability performance of firms in supply chains. By using BDAC strategically, supply chains could improve their responses to social, environmental, and social changes taking place in uncertain business environments. This paper presents a detailed literature review on the two ends of the equation: $B D A C s$ and sustainability in supply chains performance (SSCP). The theoretical perspective of the dynamic capabilities helps us to understand BDAC holistically, a combination of non-human and human capabilities. Then, we adapt the three-bottom-line approach: economic, environmental, and social performance in order to offer a comprehensive measurement of SSCP Based on the overview of the literature, the paper offers metrics to be used in assessing both BDAC and SSCP that can advance the understanding of the relationship between them.
\end{abstract}

\section{Introduction}

Big data (BD) has become a new source of competitive advantage because vast volumes of strategic, operational and tactical information consistently share across the supply chain phases. Thus, businesses need to create a strategy to utilize information produced by the supply chain management (SCM) systems [1]. With an increasingly growing volume, variety and velocity of data, conventional computing capacities, simulations, or statistics have been evolved [2, 3]. Therefore, supply chain (SC) managers started to heavily invest in sophisticated data analytics to leverage BD to extract and derive valuable insights with the potential to exceed traditional decision-making in order to achieve successful SC performance including sustainability [4].

Recent research promotes the future abilities of $\mathrm{BD}$ applications to reduce uncertainties in SC networks based on more accurate and reliable predictions [5, 6]. However, many organisations have a limited understanding of the required BD analytics (BDA) that is necessary to extract value from $\mathrm{BD}$ [7].
Therefore, the successful implementation of $\mathrm{BD}$ is required to build BDA capabilities (BDAC) integrated within SC functions [7, 8,9]. Also, a vital role of BDA for SCM is its contribution to creating relevant insights for decision-making [10, 11].

Even though literature offers many studies on how predictive analytics and data science might apply to SCM, the literature fails to actually show the direct link between BDAC and SCM [11]. Therefore, there are only a few papers that define and teste the interrelation between BDAC and operational performance [12]. For example, these limited sets of studies focus on benefits which organisations attain through using BDAC like enhancing decision making, better risk management, increasing visibility and overall more considerable value $[12,13]$.

Despite accumulating contributions have paid more attention to sustainability issues in SC, the existing literature has failed to respond to environmental, economic, and social issues[14]. However, new emerging technologies are becoming the key driver of supply chain sustainability [15]. Technologies like the internet of things (IoT) provide the ability to improved communication, coordination and cooperation between nodes of the supply chain [16] to improve the accuracy of data communication [17]. The massive volume of data generated by the IoT can be analysed by using BD analytics that may help in identifying and responding quickly to problems in the supply chain [18]. Consequently, firms seek to achieve sustainability through addressing social and environmental concerns and they hope to increase their financial performance by achieving efficiency in social and environmental performance in dynamic, complex, and uncertain environment [19]. The complexity of decision making is multiplied in a highly uncertain environment in SC [20]. As companies set out to embrace common sustainability goals, they often face information asymmetry due to the lack of collaboration between partners in supply chain networks. That is why BD provides opportunities to deal with this problem by improving the visibility and integration in $\mathrm{SC}$, which promote information sharing among partners [21]. In this light, data availability and quality are considered as a prerequisite of achieving sustainability measures as well as operational and strategic capabilities of firms 
that might be strengthened through BD analytics' support to decision-making processes within firms [19].

Some existing empirical studies indicate the influence of BDAC impact on three dimensions of the sustainability (i.e. environment, social and economic), but they are still fragmented [22]. There have been several studies on BDA for approaching environmental issues as pollutions, wastes, resource depletion, and ecology disruptions. For example, utilising BDA technologies to analyse and understand individuals' energy consumption behaviour, which leads to improve energy efficiency and promote energy conservation [23]. According to empirical performed work, there have been several studies that reveal the relationship between BDA and economic performance, for instance: profitability [24], sales growth, return on investment [25], and customer retention [26]. However, the studies related to BDA and social sustainability are scarce $[22,101]$. There is a limited number of studies indicating the role of BDA in enhancing the transparency in supply chains and mitigate the social violations to achieve social sustainability $[14,27,28]$. For example, employing of BDA can help companies to predict various social problems, including workforce health and safety, unethical behaviour, and theft. Consequently, the studies focusing on the impact of BDAC on sustainability of SC are still underdeveloped.

Our current study aims to explore BDAC and SSCP related research in extant literature. Despite recent studies in BD and SSCP, there are considerable research gaps within the existing knowledge concerning BDAC in firms as well as its impact on SSCP. The primary goal of this study explores what assessment metrics are available in literature that might be useful in future studies interested in examining the relationship between BDAC and SSCP in an empirical manner. This paper seeks to address two research questions:

RQ1: What capabilities are required to build BDA? RQ2: What constitutes the dimensions of SSCP?

This study has four sections. After this introduction, section 2 focuses on the information systems literature to examine assessments on what constitutes BDAC. Section 3 examines the supply chain literature from the triple-bottom-line (TBL) perspective in order to understand how sustainability could be observed in SC by focusing on three criteria: financial, social, and environmental performance. The paper ends with limitations of the study and suggestions for future studies.

\section{Systematic Literature Review on BDAC}

Big data (BD) has been considered as a revolution in business and management [29]due to its enormous transformational abilities to do business, management and research. Some of the previous studies widely used 5Vs (Volume, Velocity, Variety, Value and Veracity) to define big data [29-34].

Every day, new technologies such as the internet, social networking and mobile technology, create data [35]. Thus, organisations are dealing with different forms of data like customer-generated content, user logs, and customer transaction records [36]. Firms could extract business insights from BD through two stages: data management and analytics [37]. Data management stage consists of different processes: from data acquisition, recording, extraction, cleaning, and annotation to integration, aggregation, and representation. Analytics stage involves modelling, analysis, and interpretation [37].

Some authors define BDA as the process of using advanced technologies to examine $\mathrm{BD}$ in order to uncover useful information (e.g., hidden patterns.) to make better decisions across business processes among functions or companies [11]. Others focus on analytical procedures, tools, techniques, and infrastructure [38, 39]. BDA is sometimes also defined as technologies (e.g. database and data mining tools) and techniques (e.g. analytical methods) that a company can employ to analyse large-scale, complex data for various applications intended to augment firm performance in various dimensions [31, 38]. Lamba and Dubey [39] define BDA as the application of multiple analytic methods that address the diversity of big data to provide actionable, descriptive, predictive, and prescriptive results. Another study [40] defines BDA as tools and processes that often are applied to large and disperse datasets for obtaining meaningful insights.

Although BDA definitions encompass multiple success criteria for using big data, they do not involve the organisational resources that are required to transform big data into managerial actions. Therefore, scholars have begun utilising the term 'BDA capability' to reference a company's ability in leveraging big data to gain actionable insights [41].

Current BD studies have concentrated on system infrastructure: 'data capture', 'storage', 'networking' and 'distributed system parallel computing' [42, 43]. However, these studies have neglected to explore firm-specific BDAC that could be as beneficial as competencies offered by the sheer existence of system infrastructures [29, 44]. Accordingly, the BDAC concept has been proposed. It refers to "the ability of a firm to provide insights using data management, infrastructure, and talent to transform a business into a competitive force" [34]. 
BDAC is defined as "the ability of an organisation to integrate, build, and reconfigure the information resources, as well as business processes, to address rapidly changing environments" [45]. Additional studies defined BDAC as "a firm's ability to assemble, integrate, and deploy its big data-specific resources" [43]. Some studies [46, 47] suggested data management, infrastructure, and talent as critical capabilities to transform the business into a competitive force. Similarly, the core dimensions of BDA point out personnel expertise capability, infrastructure capability, and management capability [42]. Also, analytical capability and predictive analytics capability are proposed as the primary capabilities for BDAC in healthcare [24, 48]. While some research has previously investigated and introduced some BDAC, they have not offered a comprehensive picture of BDAC [41].

To shed light on the comprehensive picture of BDAC from the perspective of measuring it in empirical settings, we conducted a literature review to answer the question "what capabilities have been required to build big data analytics?" First step of the review process search Title, Keyword, and Abstract in Web of Science (WoS) and SCOPUS databases with keywords (("big data analy*") and (skill* or capabilit* or competenc*)) filtered to peer-reviewed articles in English language that published during the period of 2010 to 2018. This gave us 422 studies. After removing duplications, we had 185 papers to examine. Then, the review was narrowed down to the studies that fall into one of the five subject areas: management, business, operations research, management science, and economics. This resulted with 61 studies that were once more screened through their titles, abstracts, and keywords. We found out that only 25 studies were in line with big data analytics capabilities. Analysing these studies help us to define two key dimensions to consider while assessing BDAC, namely human and non-human capabilities. Fig.1 illustrates the procedure of literature search and selection.

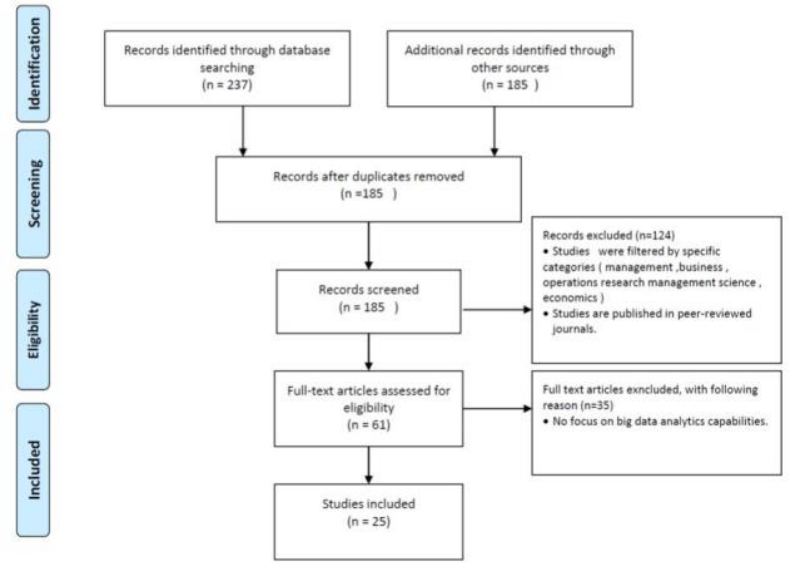

Figure 1. Systematic Literature Review on BDAC

\subsection{BDA Human capabilities}

Human capabilities are introduced as one of the BDAC by $72 \%$ of the studies [34, 49-52]. BDA highly depends on human skills and knowledge to utilise BD techniques and tools such as (data mining tools and analytical methods). Human capability refers to the professional ability of BDA staff (e.g., skills and knowledge about how to use analytical technologies and data analysis and make insight) in conducting BDA [53, 54].

According to a study [50], personnel expertise capability is the essential pillar of BDAC. Numerous research points out the scarcity of BDA professionals with knowledge and skills demanded to do this job efficiently [55, 56]. Another study [57] indicates people as a key dimension of organisational maturity regarding the adoption of big data. Review of the selected papers showed that "human capabilities" encompass both skills (technical and managerial skills) and knowledge (technological management and relational knowledge).

\subsubsection{Skills}

Past research in IT capability has indicated significant dimensions of human resources about IT, which are technical and managerial skills $[54,58]$.

Technical Skills refer to the know-how to use new technology to extract meaningful information from massive data volume [43]. Some of these skills include competencies in data extraction, machine learning, statistical analysis, data cleaning, and understanding of programming tools such as Map-Reduce [32, 43]. Observably, the most needed skills come from the disciplines of forecasting (qualitative and quantitative), optimisation, statistics (methods of estimation and sampling), economics (determining opportunity cost), mathematical modelling, and 
applied probability [59]. The firms face a significant challenge to recruit talent and train current employees in big data-specific skills, due to working with BD requires new kinds of technical and managerial skills, which are not commonly taught in universities [43].

For some businesses, the biggest challenge in deploying BDA may not be the technology itself, but how to find data scientists to work with these technologies. In 2015, IBM, Cisco, and Oracle together had 26,488 open positions that required BD expertise [60]. In Bain \& Company's survey, 56 per cent of executives said that their companies lacked the capabilities to develop deep, data-driven insights [60].

Managerial Skills form another attribute of human capability required for conducting BDA [43]. For example, analysts require to properly communicate solutions or insights driven from BD to their stakeholders [59]. Further, analyst' interaction skills have influenced on managerial decision-making processes. As a result, the valuable analytic outputs of managers' perceptions have been improved [49]. Within the context of a firm's BD function, the intelligence gathered from the data may be of no use if the managers fail to understand which gathered insights could be useful. Hence, a vital quality that data analysts should possess is the ability to predict market behaviours such as the needs of other business units, customers, and other partners [61]. Moreover, the successful use of BDAC depends on soft skills such as interpersonal skills and the ability to develop trust $[42,61]$.

\subsubsection{Knowledge}

To strengthen the human capabilities of BDAC, the firm should make organized effort to build business knowledge, technological management knowledge, technical knowledge, and relational knowledge [34, 50]. Mandal [52] indicates how BDA personnel expertise capabilities are critical enablers of supply chain agility.

Technology Management Knowledge refers to the knowledge of $\mathrm{BD}$ resources management that is necessary to support business goals [34]. Thus, it consists of both technical and business knowledge. Technical knowledge refers to the knowledge about technical elements, including operational systems, statistics, programming languages, and database management systems [62]. Business knowledge is related to the perception of various business functions and the business environment [34]. Employees who have appropriate technology management knowledge would also aid them to preserve and share their respective technical skills. Furthermore, employees would be able to enhance their business knowledge. Therefore, firms would be able to analyse changes in business conditions and develop the required solutions [52].

Relational Knowledge refers to the ability of analytics professionals "to relate, cooperate, and communicate with different kinds of people including executives, sponsors, colleagues, team members, developers, vendors, learning and development professionals, end users, customers, and subject matter experts." [[63], p. 207]. BD professionals need close relationships with other employees in the business: for example, LinkedIn developed its new feature, 'people you may know', and achieved a 30\% higher clickthrough rate [34]. Analysts also require to be able to properly communicate solutions or insights to their stakeholders - both verbally and visually [59]. Also, they require relationship skills to facilitate interaction and ongoing communication with decision makers [64] and to enable a shift from ad hoc analysis to an ongoing managerial conversation with data. The research stated that analysts' interaction skills influence managerial decision-making processes, and hence they improve managers' perceptions of the valuable analytic outputs [65].

Furthermore, a study [52] highlights the benefits of understanding the inter-relationships among BDA personnel expertise capabilities. In particular, BDA relational knowledge helps in the growth of BDA business knowledge.

\subsection{BDA Non-Human capabilities}

\subsubsection{Data}

BD makes up an important part of BDAC. The study of Gupta and George [43] indicates that the BD growth rate will lead to the growth in business data utilisation rate and it classifies data into five groups:

- Public data refer to free data owned by governmental institutions, either private organisations or individuals.

- Private data refer to data owned by corporations

- Data exhaust represents data that do not have in its context. However, data can provide valuable information when connected to other data.

- Community data refer to data generated from using social media, for instance, Facebook, Twitter.

- Self-quantification data are the personal-owned data generated from wearable technologies like fitness bands, smart watches [66].

In addition, data could be divided into external and internal data. While external data gathered from external sources, such as mobile phones, the web, ecommerce communities, and sensor, internal data are organisational data created by the organisational processes such as inventory updates and sales. Gupta and George [43] state that "firms interested in creating 
BDAC must integrate their internal and external data." This integration provides novel and more valuable insights when data are analysed.

\subsubsection{Basic resources}

The study of Gupta and George [43] explains the importance of investing both time and finance resources into BDAC. A corporate's BD investments may not start yielding the desired results immediately. It is important that managers are persistent and devote enough time to their BDA initiatives to achieve their analytical objectives. Consistent with prior information systems research [67, 68], this study suggests time and finance resources as two tangible resources required by a corporate to build a BDA capability. According to Wixom and Watson [69] study, investments and time are referred to as "resources," in order to differentiate these two resources from other resources described. In this study, we have put them under the label of "basic resources."

\subsubsection{BDA infrastructure capabilities}

BDA infrastructure capability refers to' the ability to have infrastructure such as applications and hardware to enable the BDA staff to quickly develop, deploy, and support necessary system components for a firm [53]. Infrastructure also provides the business ability to collect, store and transmit data [57]. Strengthening the BDA infrastructure's flexibility is especially essential when faced with uncertain business conditions. Infrastructure helps to align resources with long-term and short-term business strategies such as strategic alliances [34]. With a flexible infrastructure, the businesses could source and connect various data points from the remote, branch, and mobile offices; create compatible data-sharing channels across various functions, and develop models and applications to address changing needs. Therefore, the flexibility of a firm's BDAC is primarily conditioned by connectivity, compatibility, and modularity $[34,50,53]$.

\subsubsection{Organisational learning}

Sustained competitive advantage depends on the continuous process through which organisations explore store, share, and apply knowledge (Grant, 1991). In a later study, Teece argued that organisational learning is a significant source of sustained competitive advantage in a dynamic environment [70]. Nonaka claimed that knowledge might become outdated with time due to the emergence of new technologies [71]. Hence, organisations need to respond to dynamic market demand continuously. Those organisations that have the ability for learning may remain competitive in the long-term [43]. Hence, based on existing studies that organisational learning may help to build BDAC to address issues related to sustainable performance.

\subsubsection{Data-driven culture}

Organisational culture is an intangible resource, which is very difficult to understand and describe. As a result, it is hard to imitate. There are various definitions of organisational culture, but there is no agreement on a specific definition. Some researchers proclaim that organisational culture is the glue of an organisation, while others suggest it encompasses almost all areas of an organization [43]. For instance, Lavalle et al. indicate that the organisational culture is one of the reasons why big data projects are often nonproductive rather than to lack of technology and the characteristics of data [72].

To get the most value from big data, firms should develop a data-driven culture [29, 43]. A study claims that the top managers should make decisions based on data rather than intuition [29]. Thus, the efforts to collect a massive amount of data, acquire technology, and build technical and managerial skills will valuable to be success BD initiatives.

\section{Systematic Literature Review on SSCP}

Sustainable supply chain management (SSCM) concerns the voluntary integration of economic, environmental, and social dimensions where the critical inter-organisational business systems could create a coordinated supply chain to manage the information efficiently. There are several definitions for SSCM in the literature but this paper adopts the following definition for SSCM is defined as [73]:

"The creation of coordinated supply chains through the voluntary integration of economic, environmental, and social considerations with key inter-organisational business systems designed to efficiently and effectively manage the material, information, and capital flows associated with the procurement, production, and distribution of products or services in order to meet stakeholder requirements and improve the profitability, competitiveness, and resilience of the organisation over the short- and long-term".

This paper is focused on the assessment of SSCP, thus we started the review process by searching Title, Abstract and Keyword in SCOPUS with keywords ((sustainab*) AND (supply AND chain) AND (indicator OR metric OR performance OR measure)) and further restricting results to just peer reviewed articles published in English language journals during the period of 2010 to 2018 . This gave us 1,699 articles in various subject area categories. Next, we restricted 
the articles published by the top journals that have published more than five articles on SSCP: Journal of Cleaner Production, International Journal of Production Economics, Business Strategy and The Environment, International Journal of Production Research, Production Planning and Control, Journal of Manufacturing Technology Management, Supply Chain Management, Technological Forecasting and Social Change, Journal of Business Ethics. Also, we used additional filter to limit papers according to their subject category that falls into Business, Management, and Accounting. These filtering resulted in 160 articles that were all screened through their titles, abstracts, and keywords to identify papers with actionable assessment and/or metrics related to SSCP. The authors read remaining 19 papers Fig. 2 illustrates the procedure of literature search and selection.

We group the findings according to the performance dimensions in line with the TBL approach and discusses in detail in the following paragraphs.

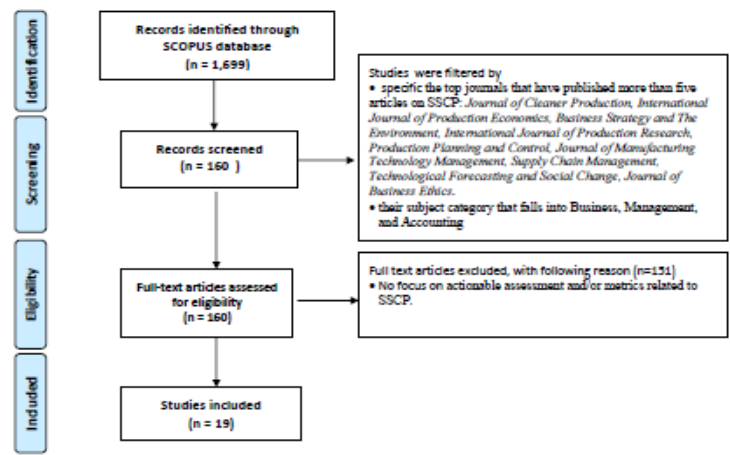

Figure 2. Systematic Literature Review on SSCP

\subsection{Social Performance}

Social sustainability has received more attention because of raising awareness about social issues such as gender discrimination, inequality, poverty, education, diversity, and wages. Big international companies, such as Apple and Nike have adopted sustainable social supply chain actions such as improving product safety, monitoring suppliers' labour practices and developing interaction with local communities [74].

Social sustainability is defined as the management of social resources that include social values, relationships and people skills and abilities [75]. In the last two decades, several issues have highlighted social sustainability in the supply chain, for instance, children and bonded labour, health and safety issues. Social sustainability in the supply chain is the response to how social problems would be approached in the supply chain. On the other hand, the role of organisations make distinguishing between social and stakeholder issues and pay attention to issues affecting the stakeholders more than society [76].

The growing pressures from government, customers, NGOs and stakeholders paid firms to more attention toward social issues in the supply chain [77]. Meanwhile, firms realized the importance of incorporating social sustainability into their business, not only at the corporate level but also at the supply chain level [78]. Thus, if firms want to improve social sustainability, they should be able to assess their performance. Yet, social sustainability is the most difficult sustainability dimension to assess due to the inability to determine which impacts should be considered [79] and how to quantify those impacts [80].

Measuring social performance focuses on the interaction between the organisation and the community as well as responses to issues that are related to community involvement, employee relations, and fair wages [81]. Generally, social performance indicators should take into account, improvement in community health and safety, rights to employees, improvement in investments on social projects (education, culture, sports), child labour, improvement in employee training and education, male vs female full time employment [82-92].

Driven from the previous studies, we classify the social performance into seven sub-categories: health and safety, employment benefits, labour rights, community human rights implementation and integration, diversity, training, education, and personal skills [92-94].

\subsection{Environmental Performance}

Environmental sustainability has become a significant topic not only for academia but also for industries [95] due to two main drivers: environmental legislation and customer demand for environmentally friendly services and products. Environmental performance assesses the extent to which companies meet the expectations of their stakeholders regarding environmental responsibility through the efficient utilisation of energy resources and the minimisation of ecological footprints [96]. In the same line, the extent to which an organisation improves outcomes related to pollution control and environmental management [97, 98].

Profit-maximising is the primary driver for companies which cause many environmental problems [91] lead to increasingly pressed to minimise the ecological footprint of companies [99]. However, this issue extends beyond firms to include its entire supply 
chain. Unethical behaviours of supply chain partners damage the brand image of international corporations. For example, Nestle was accused of rainforest deforestation through its palm oil suppliers. Therefore, closely working corporations with their supply chain partners will lead to providing sustainable products and services [100]. Environmental standards may be implemented in two ways: as environmental practices (policies and procedures such as monitoring discharge and conducting periodical audits) and as environmental performance measurements (e.g., pollution control and resource utilized).

Generally, environmental performance indicators should take into account, reduction in air pollution, decrease in consumption of hazardous/harmful/toxic materials, decrease in use of natural resources, increase in energy saved due to conservation and efficiency improvements [82-92].

According to systematic literature review, we classify the environmental performance into two subcategories: pollution control and resource utilized [101].

\subsection{Economic performance}

Managers have a fiduciary responsibility to adopt sustainability practices based on business self-interest and return on investment principles [102]. However, more efficient and effective use of resources, which will improve economic performance and will lead to achieving economic development as well as economic sustainability [103]. Similarly, the alignment between economic objectives and a long-term strategy will help to create a difficult-to-imitate competitive advantage [104].

The economic sustainability means how could consistently keep the profit generated from human, nature, and society. Within a corporate context, economic sustainability means improvement the shortterm and long-term shareholders' value as well as the building a strong financial foundation for the continued survival of a company [105]. We can notice the domination of decision-related cost or 'total" costbased and revenue approaches in the economic dimension. Empirically, Green and Zelbst [106] reveal that the developed economic performance dimension is mainly related to reducing costs associated with energy consumption, purchased materials, waste discharge, waste treatment, and disposal. There are different indicators of economic performance can be measured from various perspectives including: decrease in cost of energy consumption, growth in profit, amount of goods delivered on time, decrease in fee for waste discharge [82-92].
According to previous studies, we present the metrics for economic performance in four sub-categories: time, cost, quality, and profit [92].

\section{Concluding Remarks}

This paper reviews existing literature and explores assessment metrics used to measure BDAC and SSCP. Future studies might use them to shed light on the relationship between BDAC and SSCP, which might contribute to understanding how sustainability of companies might improve through the utilization of new technologies.

Reviewing of BDAC literature provides a new definition and classification of BDAC. Previous studies have not offered a comprehensive picture of BDAC only focus on non-human capabilities. This study tries to fill a gap through new classification involves human and non-human capabilities.

While the former one encompasses both skills (technical and managerial skills) and knowledge (technological management and relational knowledge), the latter one is based on data, basic resources, BDA infrastructure capabilities, organizational learning, and data-driven culture.

In addition, our literature review suggests the following multi-dimensional measurement metrics to be used for the assessment of each SSCP dimension suggested by the TBL theory: (1) health \& safety, employment benefits, labour rights, community, human rights implementation \& integration, diversity, training, education, and personal skills for social performance; (2) time, cost, quality, and profit metrics for economic performance; and (3) pollution control and utilization of resources for environmental performance.

Being a conceptual paper based on literature review, the study has two limitations that might be opportunities for researchers in BDAC literature. First, it is an overview of literature that could lay the base to develop a framework to examine the relationship between BDAC and SSCP. Second, the study is concentrated on understanding how to measure BDAC and SSCP, but it leaves aside potential moderator factors that could affect the relationship between BDAC and SSCP. Conducting empirical work in different industry settings and countries could enrich the knowledge on assessing BDAC and SSCP individually as well as the impact of BDAC on SSCP. Similarly, further studies might expand the scope to search for additional factors that might play pivotal role in the realization of the impact of BDAC on SSCP. 


\section{References}

1. Klein, N., No logo. 2009: Vintage Books Canada.

2. Chen, C.P. and C.-Y. Zhang, Data-intensive applications, challenges, techniques and technologies. Information Sciences, 2014. 275: p. 314-347

3. Wang, G., et al., Big data analytics in logistics and supply chain management. International Journal of Production Economics, 2016. 176: p. 98-110.

4. Sanders, N.R., How to use big data to drive your supply chain. California Management Review, 2016. 58(3): p. 26-48.

5. Chong, A.Y.L., et al., Predicting online product sales via online reviews, sentiments, and promotion strategies. International Journal of Operations \& Production Management, 2016. 36(4): p. 358-383.

6. Sagaert, Y., et al. Sales Forecasting with Temporal Big Data. in Informs International. 2016.

7. Arunachalam, D., N. Kumar, and J.P. Kawalek, Understanding big data analytics capabilities in supply chain management. Transportation Research Part E-Logistics and Transportation Review, 2018. 114: p. 416-436.

8. Akhtar, P., et al., Essential Micro-foundations for Contemporary Business Operations. British Journal of Management, 2018. 29(1): p. 43-62.

9. GalbRaith, J.R., Organizational design challenges resulting from big data. Journal of Organization Design, 2014. 3(1): p. 2-13.

10. Hazen, B.T., et al., Data quality for data science, predictive analytics, and big data in supply chain management. International Journal of Production Economics, 2014. 154: p. 72-80.

11. Waller, M.A. and S.E. Fawcett, Data science, predictive analytics, and big data. Journal of Business Logistics, 2013. 34(2): p. 77-84.

12. Chae, B.K., et al., The impact of advanced analytics and data accuracy on operational performance. Decision support systems, 2014. 59: p. 119-126.

13. Lycett, M., 'Datafication': making sense of (big) data in a complex world. 2013, Taylor \& Francis.

14. Song, M., et al., How would big data support societal development and environmental sustainability? Insights and practices. Journal of Cleaner Production, 2017. 142: p. 489-500.

15. Kamble, S.S., A. Gunasekaran, and S.A. Gawankar, Sustainable Industry 4.0 framework. Process Safety and Environmental Protection, 2018. 117: p. 408-425.

16. Ahumada, O. and J.R. Villalobos, Application of planning models in the agri-food supply chain. European Journal of Operational Research, 2009. 196(1): p. 1-20.

17. de Vass, T., The "Internet of Things" enabled supply chain integration and performance. 2018, Victoria University.

18. Verdouw, C.N., et al., Virtualization of food supply chains with the internet of things. Journal of Food Engineering, 2016. 176: p. 128-136.

19. Hazen, B.T., et al., Big Data and predictive analytics for supply chain sustainability. Computers \& Industrial Engineering, 2016. 101: p. 592-598.

20. Wu, Z. and M. Pagell, Balancing priorities. Journal of Operations Management, 2011. 29(6): p. 577-590.

21. Dubey, R., et al., Examining the role of big data and predictive analytics on collaborative performance in context to sustainable consumption and production behaviour. Journal of Cleaner Production, 2018. 196: p. 1508-1521.

22. Song, W., X. Ming, and H.-C. Liu, Identifying critical risk factors of sustainable supply chain management. Journal of Cleaner Production, 2017. 143: p. 100-115.

23. Koseleva, N. and G. Ropaite, Big Data in Building Energy Efficiency. Procedia Engineering, 2017. 172: p. 544-49.
24. Wang, Y.C., L. Kung, and T.A. Byrd, Big data analytics. Technological Forecasting and Social Change, 2018. 126: p. 3-13. 25. Court, D., Getting big impact from big data. McKinsey Quarterly, 2015. 1(1): p. 52-60.

26. Davenport, T.H., Competing on analytics. harvard business review, 2006. 84(1): p. 98.

27. Wu, J., et al., Big Data Meet Green Challenges. IEEE Systems Journal, 2016. 10(3): p. 888-900.

28. Keeso, A., Big data and environmental sustainability. Smith School of Enterprise and the Environment. Working Paper Series, 2014(14-04).

29. McAfee, A., et al., Big data: the management revolution. Harvard business review, 2012. 90(10): p. 60-8.

30. Burke, B., Gamification: Engagement strategies for business and IT. Gartner Research, 2012.

31. Kwon, O. and J.M. Sim, Effects of data set features on the performances of classification algorithms. Expert Systems with Applications, 2013. 40(5): p. 1847-1857.

32. Russom, P., Big data analytics. TDWI best practices report, fourth quarter, 2011. 19(4): p. 1-34.

33. Wamba, S.F., et al., How 'big data'can make big impact. International Journal of Production Economics, 2015. 165: p. 234246.

34. Akter, S., et al., How to improve firm performance using big data analytics capability and business strategy alignment? International Journal of Production Economics, 2016. 182: p. 113131.

35. Kauffman, J.B. and D.C. Donato, Protocols for the measurement, monitoring and reporting of structure, biomass, and carbon stocks in mangrove forests. 2012: Citeseer.

36. Chen, H.C., R.H.L. Chiang, and V.C. Storey, Business Intelligence and Analytics. Mis Quarterly, 2012. 36(4): p. 11651188.

37. Gandomi, A. and M. Haider, Beyond the hype. International journal of information management, 2015. 35(2): p. 137-144.

38. Kwon, O., N. Lee, and B. Shin, Data quality management, data usage experience and acquisition intention of big data analytics. International journal of information management, 2014. 34(3): p. 387-394.

39. Lamba, H.S. and S.K. Dubey. Analysis of requirements for big data adoption to maximize IT business value. in Reliability, Infocom Technologies and Optimization (ICRITO)(Trends and Future Directions), 2015 4th International Conference on. 2015. IEEE.

40. Ghasemaghaei, M. and K. Hassanein, Online information quality and consumer satisfaction. Information \& Management, 2015. 52(8): p. 965-981.

41. Mikalef, P., et al., Big data analytics capabilities: a systematic literature review and research agenda. Information Systems and EBusiness Management, 2018. 16(3): p. 547-578.

42. Kearns, G.S. and A.L. Lederer, A resource-based view of strategic IT alignment. Decision sciences, 2003. 34(1): p. 1-29.

43. Gupta, M. and J.F. George, Toward the development of a big data analytics capability. Information \& Management, 2016. 53(8): p. 1049-1064.

44. Shuradze, G. and H.-T. Wagner. Towards a conceptualization of data analytics capabilities. in 2016 49th Hawaii International Conference on System Sciences (HICSS). 2016. IEEE.

45. Olszak, C.M. Towards an understanding Business Intelligence. in Computer Science and Information Systems (FedCSIS), 2014 Federated Conference on. 2014. IEEE.

46. Wamba, S.F., et al., Big data analytics and firm performance. Journal of Business Research, 2017. 70: p. 356-365.

47. Chae, B. and D.L. Olson, Business analytics for supply chain. International Journal of Information Technology \& Decision Making, 2013. 12(01): p. 9-26. 
48. Wang, Y.C. and N. Hajli, Exploring the path to big data analytics success in healthcare. Journal of Business Research, 2017. 70: p. 287-299.

49. Barbosa, M.W., et al., Managing supply chain resources with Big Data Analytics. International Journal of Logistics-Research and Applications, 2018. 21(3): p. 177-200.

50. Wamba, S.F., et al., Big data analytics and firm performance: Effects of dynamic capabilities. Journal of Business Research, 2017. 70: p. 356-365.

51. Wang, Y.C., et al., An integrated big data analytics-enabled transformation model. Information \& Management, 2018. 55(1): p. 64-79.

52. Mandal, S., An examination of the importance of big data analytics in supply chain agility development:. Management Research Review, 2018. 41(10): p. 1201-1219.

53. Kim, G., B. Shin, and O. Kwon, Investigating the Value of Sociomaterialism in Conceptualizing IT Capability of a Firm. Journal of Management Information Systems, 2012. 29(3): p. 327-362.

54. Bharadwaj, A.S., A resource-based perspective on information technology capability and firm performance: an empirical investigation. MIS quarterly, 2000: p. 169-196.

55. Dubey, R. and A. Gunasekaran, Education and training for successful career in Big Data and Business Analytics. Industrial and Commercial Training, 2015. 47(4): p. 174-81.

56. Rialti, R., et al., Ambidextrous organization and agility in big data era. Business Process Management Journal, 2018. 24(5): p. 1091-1109.

57. Coleman, S., et al., How Can SMEs Benefit from Big Data? Quality and Reliability Engineering International, 2016. 32(6): p. 2151-64.

58. Chae, H.-C., C.E. Koh, and V.R. Prybutok, Information technology capability and firm performance. MIS Quarterly, 2014. 38(1): p. 305-326.

59. Davenport, T., Big data at work: dispelling the myths, uncovering the opportunities. 2014: Harvard Business Review Press.

60. Grover, V., et al., Creating Strategic Business Value from Big Data Analytics: A Research Framework. Journal of Management Information Systems, 2018. 35(2): p. 388-423.

61. Mata, F.J., W.L. Fuerst, and J.B. Barney, Information technology and sustained competitive advantage: A resourcebased analysis. MIS quarterly, 1995: p. 487-505.

62. Davenport, T.H. and D. Patil, Data scientist. Harvard business review, 2012. 90(5): p. 70-76.

63. Brennan, K., A Guide to the Business Analysis Body of Knowledger. 2009: liba.

64. Davenport, T.H. and J.G. Harris, Competing on analytics: The new science of winning. 2007: Harvard Business Press.

65. Thirathon, U., B. Wieder, and M.L. Ossimitz, Determinants of analytics-based managerial decision-making. ljispm-International Journal of Information Systems and Project Management, 2018. 6(1): p. 27-40.

66. George, G., M.R. Haas, and A. Pentland, Big Data and Management. Academy of Management Journal, 2014. 57(2): p. 321-326.

67. Mata, F.J., W.L. Fuerst, and J.B. Barney, Information Technology and Sustained Competitive Advantage. MIS Quarterly, 1995. 19(4): p. 487-505.

68. Wixom, B.H. and H.J. Watson, An Empirical Investigation of the Factors Affecting Data Warehousing Success. MIS Quarterly, 2001. 25(1): p. 17-41.

69. Wixom, B.H. and H.J. Watson, An empirical investigation of the factors affecting data warehousing success. MIS quarterly, 2001: p. 17-41.
70. Teece, D.J., G. Pisano, and A. Shuen, Dynamic capabilities and strategic management. Strategic management journal, 1997. 18(7): p. 509-533.

71. Nonaka, I., R. Toyama, and A. Nagata, A firm as a knowledgecreating entity. Industrial and corporate change, 2000. 9(1): p. 120.

72. LaValle, S., et al., Big data, analytics and the path from insights to value. MIT sloan management review, 2011. 52(2): p. 21.

73. Ahi, P. and C. Searcy, A comparative literature analysis of definitions for green and sustainable supply chain management. Journal of cleaner production, 2013. 52: p. 329-341.

74. Klassen, R.D. and A. Vereecke, Social issues in supply chains. International Journal of production economics, 2012. 140(1): p. 103-115.

75. Sarkis, J., M.M. Helms, and A.A. Hervani, Reverse logistics and social sustainability. Corporate Social Responsibility and Environmental Management, 2010. 17(6): p. 337-354.

76. Clarkson, M.E., A stakeholder framework for analyzing and evaluating corporate social performance. Academy of management review, 1995. 20(1): p. 92-117.

77. Mani, V., et al., Supply chain social sustainability for developing nations. Resources, Conservation and Recycling, 2016. 111: p. 42-52.

78. Vachon, S. and Z. Mao, Linking supply chain strength to sustainable development. Journal of Cleaner Production, 2008. 16(15): p. 1552-1560.

79. Hutchins, M.J. and J.W. Sutherland, An exploration of measures of social sustainability and their application to supply chain decisions. Journal of Cleaner Production, 2008. 16(15): p. 1688-1698.

80. Beske-Janssen, P., M.P. Johnson, and S. Schaltegger, 20 years of performance measurement in sustainable supply chain management. Supply Chain Management, 2015. 20(6): p. 664-680. 81. Goel, P., Triple Bottom Line Reporting. Journal of Finance, Accounting \& Management, 2010. 1(1).

82. Ahi, P. and C. Searcy, An analysis of metrics used to measure performance in green and sustainable supply chains. Journal of Cleaner Production, 2015. 86: p. 360-77.

83. Das, D., Sustainable supply chain management in Indian organisations. International Journal of Production Research, 2018. 56(17): p. 5776-5794.

84. Dubey, R., et al., Can big data and predictive analytics improve social and environmental sustainability? Technological Forecasting and Social Change, 2017.

85. Esfahbodi, A., Y. Zhang, and G. Watson, Sustainable supply chain management in emerging economies. International Journal of Production Economics, 2016. 181: p. 350-366.

86. Esfahbodi, A., et al., Governance pressures and performance outcomes of sustainable supply chain management-An empirical analysis of UK manufacturing industry. Journal of cleaner production, 2017. 155: p. 66-78.

87. Feng, M., et al., Green supply chain management and financial performance. Business Strategy and the Environment, 2018. 27(7): p. 811-824.

88. Kumar, D. and Z. Rahman, Buyer supplier relationship and supply chain sustainability. Journal of Cleaner Production, 2016. 131: p. 836-848.

89. Kumar, G., N. Subramanian, and R. Maria Arputham, Missing link between sustainability collaborative strategy and supply chain performance. International Journal of Production Economics, 2018. 203: p. 96-109.

90. Luthra, S., D. Garg, and A. Haleem, The impacts of critical success factors for implementing green supply chain management towards sustainability. Journal of Cleaner Production, 2016. 121: p. 142-158. 
91. Paulraj, A., I.J. Chen, and C. Blome, Motives and performance outcomes of sustainable supply chain management practices. Journal of Business Ethics, 2017. 145(2): p. 239-258.

92. Tajbakhsh, A. and E. Hassini, Performance measurement of sustainable supply chains. International Journal of Productivity and Performance Management, 2015. 64(6): p. 744-783.

93. Mani, V., A. Gunasekaran, and C. Delgado, Enhancing supply chain performance through supplier social sustainability. International Journal of Production Economics, 2018. 195: p. 259272.

94. Popovic, T., et al., Quantitative indicators for social sustainability assessment of supply chains. Journal of cleaner production, 2018. 180: p. 748-768.

95. Brandenburg, M., et al., Quantitative models for sustainable supply chain management. European journal of operational research, 2014. 233(2): p. 299-312.

96. Elkington, J., Cannibals with forks. Capstone. 1997, Oxford. 97. Pullman, M.E., M.J. Maloni, and C.R. Carter, Food for thought. Journal of Supply Chain Management, 2009. 45(4): p. 38-54.

98. Jacobs, B.W., V.R. Singhal, and R. Subramanian, An empirical investigation of environmental performance and the market value of the firm. Journal of Operations Management, 2010. 28(5): p. 430-441.

99. Morali, O. and C. Searcy, A review of sustainable supply chain management practices in Canada. Journal of business ethics, 2013. 117(3): p. 635-658.

100. Gold, S., S. Seuring, and P. Beske, Sustainable supply chain management and inter-organizational resources: a literature review. Corporate social responsibility and environmental management, 2010. 17(4): p. 230-245.

101. Hong, J., Y. Zhang, and M. Ding, Sustainable supply chain management practices, supply chain dynamic capabilities, and enterprise performance. Journal of Cleaner Production, 2018. 172 p. 3508-3519.

102. Siegel, D.S., Green management matters only if it yields more green. The Academy of Management Perspectives, 2009: p. 5-16.

103. Singa Boyenge, J.-P., ILO database on export processing zones (Revised). 2007, ILO.

104. Carter, C.R. and D.S. Rogers, A framework of sustainable supply chain management. International journal of physical distribution \& logistics management, 2008. 38(5): p. 360-87.

105. Steurer, R., et al., Corporations, stakeholders and sustainable development I. Journal of business ethics, 2005. 61(3): p. 263-281. 106. Green Jr, K.W., et al., Green supply chain management practices: impact on performance. Supply Chain Management: An International Journal, 2012. 17(3): p. 290-305.

107. Huo, B., M. Gu, and Z. Wang, Green or lean?. Journal of Cleaner Production, 2019. 216: p. 152-166.

108. Khan, S.A., et al., Supplier sustainability performance evaluation and selection. Journal of Cleaner Production, 2018. 205: p. 964-79.

109. Rashidi, K. and R.F. Saen, Incorporating dynamic concept into gradual efficiency. Journal of Cleaner Production, 2018. 202: $p$. 226-243.

110. Silva, G.M., P.J. Gomes, and J. Sarkis, The role of innovation in the implementation of green supply chain management practices. Business Strategy and the Environment, 2019. 0(0).

111. Yildiz Çankaya, S. and B. Sezen, Effects of green supply chain management practices on sustainability performance. Journal of Manufacturing Technology Management, 2019. 30(1): p. 98-121. 112. Hassini, E., C. Surti, and C. Searcy, A literature review and a case study of sustainable supply chains with a focus on metrics. International Journal of Production Economics, 2012. 140(1): p. 6982.
113. Singh, S.K. and A.-N. El-Kassar, Role of big data analytics in developing sustainable capabilities. Journal of Cleaner Production, 2019. 213: p. 1264-1273.

114. Qorri, A., Z. Mujkić, and A. Kraslawski, A conceptual framework for measuring sustainability performance of supply chains. Journal of Cleaner Production, 2018. 189: p. 570-84.

115. Burki, U., P. Ersoy, and R. Dahlstrom, Achieving triple bottom line performance in manufacturer-customer supply chains. Journal of Cleaner Production, 2018. 197: p. 1307-16.

116. Wang, Y.C. and T.A. Byrd, Business analytics-enabled decisionmaking effectiveness through knowledge absorptive capacity in health care. Journal of Knowledge Management, 2017. 21(3): p. 517-539.

117. Caesarius, L.M. and J. Hohenthal, Searching for big data How incumbents explore a possible adoption of big data technologies. Scandinavian Journal of Management, 2018. 34(2): p. 129-140.

118. Chaurasia, S.S. and A.F. Rosin, From Big Data to Big Impact. Industrial and Commercial Training, 2017. 49(7-8): p. 321-328.

119. Dremel, C., et al., How AUDI AG Established Big Data Analytics in Its Digital Transformation. Mis Quarterly Executive, 2017. 16(2): p. 81-100.

120. Ghasemaghaei, M., S. Ebrahimi, and K. Hassanein, Data analytics competency for improving firm decision making performance. Journal of Strategic Information Systems, 2018. 27(1): p. 101-113.

121. Sedkaoui, S., How data analytics is changing entrepreneurial opportunities? International Journal of Innovation Science, 2018. 10(2): p. 274-294.

122. Giannakis, M. and M. Louis, A multi-agent based system with big data processing for enhanced supply chain agility. Journal of Enterprise Information Management, 2016. 29(5): p. 706-727.

123. Lai, Y.Y., H.F. Sun, and J.F. Ren, Understanding the determinants of big data analytics (BDA) adoption in logistics and supply chain management. International Journal of Logistics Management, 2018. 29(2): p. 676-703.

124. Ren, S.J.F., et al., Modelling quality dynamics, business value and firm performance in a big data analytics environment. International Journal of Production Research, 2017. 55(17): p. 5011-5026. 